\title{
The Intra-Tidal Characteristics of Tidal Front and Their Spring-Neap Tidal and Seasonal Variations in Bungo Channel, Japan
}

\author{
Menghong Dong (D) and Xinyu Guo *(D) \\ Center for Marine Environmental Studies (CMES), Ehime University, Matsuyama 790-8577, Japan; \\ f870003b@mails.cc.ehime-u.ac.jp \\ * Correspondence: guoxinyu@sci.ehime-u.ac.jp; Tel.: +81-89-927-9824
}

check for updates

Citation: Dong, M.; Guo, X. The Intra-Tidal Characteristics of Tidal Front and Their Spring-Neap Tidal and Seasonal Variations in Bungo Channel, Japan. Remote Sens. 2021, 13, 1840. https://doi.org/10.3390/ rs13091840

Academic Editor: Kaoru Ichikawa

Received: 24 March 2021

Accepted: 6 May 2021

Published: 9 May 2021

Publisher's Note: MDPI stays neutral with regard to jurisdictional claims in published maps and institutional affiliations.

Copyright: (c) 2021 by the authors. Licensee MDPI, Basel, Switzerland. This article is an open access article distributed under the terms and conditions of the Creative Commons Attribution (CC BY) license (https:/ / creativecommons.org/licenses/by/ $4.0 /)$.

\begin{abstract}
The intra-tidal variations of a tidal front in Bungo Channel, Japan and their dependence on the spring-neap tidal cycle and month were analyzed utilizing high-resolution $(\sim 2 \mathrm{~km})$ hourly sea surface temperature (SST) data obtained from a Himawari-8 geostationary satellite from April 2016 to August 2020. A gradient-based front detection method was utilized to define the position and intensity of the front. Similar to previous ship-based studies, SST data were utilized to identify tidal fronts between a well-mixed strait and its surrounding stratified area. The hourly SST data confirmed the theoretical intra-tidal movement of the tidal front, which is mainly controlled by tidal current advection. Notably, the intensity of the front increases during the ebb current phase, which carries the front toward the stratified area, but decreases during the flood current phase that drives the front in the opposite direction. Due to a strong dependence on tidal currents, the intra-tidal variations appear in a fortnight cycle, and the fortnightly variations of the front are dependent on the month in which the background stratification and residual current changes occur. Additionally, tidal current convergence and divergence are posited to cause tidal front intensification and weakening.
\end{abstract}

Keywords: sea surface temperature; tidal front; intra-tidal variations; tidal current

\section{Introduction}

A front forms where two different water masses converge; there are many types of fronts in the shelf sea, which are classified into three types according to where they are formed [1]. Tidal fronts form in the transition area between vertical mixed water and stratified water, caused by tidal stirring and surface heating, respectively, and primarily occur in summer. Simpson and Hunter [2] first reported the tidal front in the Irish Sea, and many observational and modeling studies have been performed on the fronts in the Irish, Celtic, North, and Seto Inland Seas. Earlier studies focused on the formation and seasonal variations of the fronts and then shifted to front instability and its relationship to biological processes [3-14]. The Simpson and Hunter [2] parameter, derived from a balance between the potential energy increase due to surface heating (at rate $\dot{Q}$ ) and turbulent kinetic energy dissipation induced by tidal stirring, is an effective method for understanding the location of a front. The parameter is $\dot{Q} h / u^{3}$, where $\mathrm{h}$ is the water depth and $u$ is the tidal current amplitude. Because $\dot{Q}$ may be regarded as spatially uniform in coastal waters, the tidal front position depends on the value of $h / u^{3}$.

Changes in heating and stirring rates in the movement of the tidal front result in a new position if a constant value of the above parameter is applied to the front. Simpson and Bowers [15] determined that the seasonal variations in the position of the tidal fronts in the Irish and Celtic Seas are minimal, although the heating rates vary significantly in summer. They proposed a feedback effect in which the stratification reduced the tidal stirring efficiency and utilized this theory to explain the small seasonal variation in the tidal front position. Utilizing ship-based observational data, Yanagi and Tamaru [5] reported 
the seasonal variations of a tidal front in the Bungo Channel (Figure 1) that forms in early April; its mean position remains unchanged from May to August, although it undergoes a wide range of intensity changes.
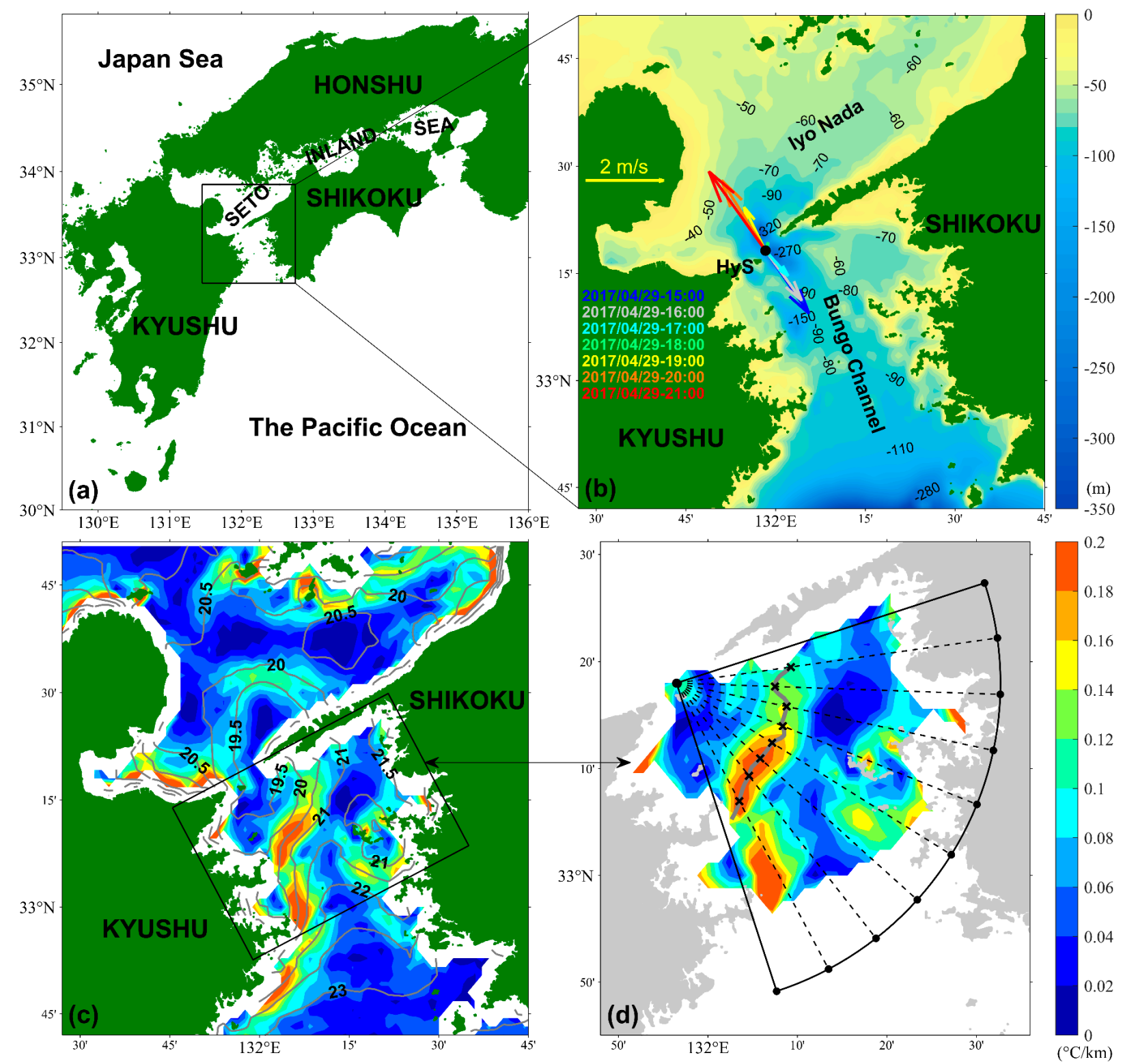

Figure 1. (a) Study area location. (b) Enlarged map of the study area showing the bathymetry from ETOPO1 of the Bungo Channel and Iyo Nada. The black dot indicates the location where the tidal current was synthesized by harmonic constants. Arrows mean the synthesized tidal current for 6 hours from maximum ebb current (15:00 29 April 2017) to maximum flood current (21:00 29 April 2017) during one spring tide. "HyS" denotes Hayasui Strait. (c) Tidal front location near Hayasui Strait. Contours indicate monthly average sea surface temperature $\left(\mathrm{SST},{ }^{\circ} \mathrm{C}\right)$ in June, and colors indicate the magnitude of the horizontal gradient $\left({ }^{\circ} \mathrm{C} / \mathrm{km}\right)$. (d) Schematic of the method utilized to determine tidal front position. Colors indicate the magnitude of the SST gradient. There are 45 sectors, each with a $2^{\circ}$ angle. The figure shows every five sectors with dashed lines. The black " $\mathrm{X}$ " symbols indicate the position of the front where the maximum magnitude of the SST gradient along each broken line occurs.

Simpson and James [11] proposed that the movement of the front during a springneap tidal cycle should correspond to variations in tidal stirring power, i.e., the front is located near the stratified area during spring tide when the tidal current is strong but located near the mixed area during neap tide when the tidal current is weak. However, the 
feedback effect proposed by Simpson and Bowers [15] limits tidal front movement during the spring-neap tidal cycle. The stratification during neap tide reduces the mixing efficiency during spring tide; therefore, the stratification is retained, restricting the movement of the front to the stratified area during spring tide. For the tidal front in the Bungo Channel, Yanagi and Tamaru [5] noted that the front moves closer to the well-mixed strait during neap tide than during spring tide, and its intensity increases from neap tide to spring tide. However, the reported fortnightly variations of the front may contain intra-tidal variations because the sampling period of the observational data utilized was longer than the tidal periods. The tidal front modeling study by Sun and Isobe [16] suggested that the intensity of the front varies over a 15-day period, during which the front is destroyed by growing frontal waves during neap tide and restored during spring tide when strong tidal currents reconstruct mixed regions.

In addition to variations in tidal currents, wind- and density-driven currents also affect the tidal front. Wang et al. [14] reported no fortnightly variation in the tidal front between the well-mixed Irish Sea and the stratified Celtic Sea and that the tidal front was mainly controlled by wind. Wind-driven advection of well-mixed waters over warmer stratified water causes convective instability and weakening of the surface front [14]. The horizontal gradients in the density-driven current can act to promote the development of the frontogenesis [17]. In addition to the influence of current, the input of fresh water also affects the formation of the tidal front by strengthening the stratification [18]. Although there are many studies on the seasonal and fortnightly variations of tidal fronts, intratidal variations have been minimally studied and are poorly understood. It is difficult to determine how tidal fronts change in a tidal cycle from observational data due to its limited temporal resolution. The positional change in the tidal front in a tidal period is theoretically expected; however, it has not been well documented using observational data. Furthermore, understanding how the tidal front intensity changes with the tidal phase is minimally understood. Without a full description of the tidal front intra-tidal variations, its temporal change over a long period cannot be thoroughly understood because the observations were probably under-sampled if the field had significant intra-tidal variations.

For the tidal front in Bungo Channel, which is one the main channels connecting the Seto Inland Sea and the Pacific Ocean, the water in the northern part of this front was well mixed vertically due to the strong tidal current whose amplitude is up to $2.5-3.0 \mathrm{~m} / \mathrm{s}$ near Hayasui Strait, while the water in the southern part was stratified due to weak tidal current (Figure 1). The water depth in the strait is about $300 \mathrm{~m}$, while that in the middle part of the channel is about $100 \mathrm{~m}$ (Figure 1b). For the physical aspect of the tidal front, although the seasonal variations and fortnightly variations have been examined by Yanagi and Tamaru [5] using ship-based observational data, the intra-tidal variations are still unclear. For the chemical and biological aspects around the front, Yanagi et al. [19] reported that man-made organic chemicals such as polychlorinated biphenyls (PCBs) are concentrated in the surface water around the front; nutrients are richer in the well-mixed region than in the surface water of the stratified region; neuston such as marine skaters are accumulated along the front, and the tidal front plays as a barrier for some oceanic and neritic pontellid copepods. In addition, there was a water intrusion around the front from the mixed water to the middle layer of the stratified water, and this intrusion was supposed to be an important process supplying nutrients from the mixed water to the subsurface of the frontal region and causing the intense chlorophyll a maximum [6]. The alternation between homogeneous and vertically stratified water, usually associated with tidal fronts, impacts on availability of light and nutrients, thus enhancing marine primary productivity [20]. Consequently, the tidal front region tends to be associated with higher trophic organisms such as jelly fish and fishes. Given this significant role of tidal front on the coastal ecology and circulation, it is important to quantify and understand the variations of the front from intra-tidal scales to seasonal scales. In this study, an hourly sea surface temperature (SST) dataset over five years was utilized to clarify the intra-tidal variations of a tidal front and re-examine its fortnightly and seasonal variations utilizing fully sampled data. 


\section{Data and Method}

To explore the intra-tidal variations of a tidal front, SST data with a minimum interval of $1 \mathrm{~h}$ are required, while small-scale tidal fronts in coastal areas require high spatial resolution data. From 7 July 2015, the satellite Himawari-8, a geostationary meteorological satellite and launched by Japan Meteorological Agency (JMA), became operational. This satellite is located at $140.7^{\circ} \mathrm{E}$ and observes the Earth for an area from $80^{\circ} \mathrm{E}$ to $160^{\circ} \mathrm{W}$ and from $60^{\circ} \mathrm{N}$ to $60^{\circ} \mathrm{S}$. The Advanced Himawari Imager (AHI) is an optical radiometer onboard the Himawari-8. The AHI has 16 spectral bands from visible to infrared (IR) wavelengths. The IR bands centered at 3.9, 8.6, 10.4, 11.2, and $12.4 \mu \mathrm{m}$ are usable for sea surface temperature (SST) retrieval.

The Earth Observation Research Center of the Japan Aerospace Exploration Agency (JAXA) released a skin SST dataset that was used in this study retrieved from 10.4, 11.2, and $8.6 \mu \mathrm{m}$ data of the Himawari-8 satellite in nearly real time [21]. Kurihara et al. [22] compared the SST data from the Himawari-8 satellite with data obtained from drifting and tropical-moored buoys and determined a root-mean-square difference and bias of $\sim 0.59$ and $\sim-0.16 \mathrm{~K}$, respectively, which agrees with the mean difference between the skin and bulk temperatures reported by Donlon et al. [23]. The Himawari-8 satellite data have a spatial resolution of $2 \mathrm{~km}$ and a temporal interval of $1 \mathrm{~h}$, which allows the tidal front intra-tidal variations to be examined.

This study utilized SST data from April 2016 to August 2020 downloaded from the JAXA website [21]. Due to cloud presence, SST data are not always available in the study area (black box in Figure 1c). By utilizing a standard that the data must cover more than $90 \%$ of the target area, 1233, 998, 610, 632, and 1246 data scenes for April to August, respectively, were selected from the entire dataset covering five years. It must be noted that we did not consider the difference between daytime and night-time of SST in this study. On one hand, if we select only the night-time data for analysis, the data scenes for each month will be too few. On the other hand, as given in Equation (1), we use the gradient of SST to identify the position and intensity of the tidal front. Because of its large spatial scale, the difference of daytime and night-time is expected to have little influence on the gradient of SST around the front.

The SST data were used to identify the position and intensity of a tidal front. In this study, the magnitude $\left(T_{G}\right)$ of the SST gradient was utilized to define the intensity of the tidal front as follows:

$$
T_{G}=\sqrt{\left(\frac{\partial T}{\partial x}\right)^{2}+\left(\frac{\partial T}{\partial y}\right)^{2}},
$$

where $T$ is the SST, and $x$ and $y$ are the eastward and northward coordinators, respectively. The tidal front position was determined in a tilted rectangular area in the Bungo Channel, with an area of approximately $65 \times 45 \mathrm{~km}$ (black box in Figure 1c), and in this area, the tidal current was the strongest inside the Hayasui Strait. As the strait is exited to the south, the tidal current gradually weakens, consequently forming stratification; therefore, the Hayasui Strait was considered as the reference point, and an arc area with an angle of $90^{\circ}$ was defined from the center at the strait (Figure 1d). This arc area was divided into 45 portions at $2^{\circ}$ intervals (Figure $1 \mathrm{~d}$ ), obtaining 46 rays from the center to the edge of the arc; therefore, during tidal front formation, 46 points with a maximum $T_{G}$ along each ray $\left(T_{G f},{ }^{\circ} \mathrm{C} / \mathrm{km}\right)$ denote the position of the tidal front.

In this study, the distance, $D_{f}$ (unit, $\mathrm{km}$ ), between the point with maximum $T_{G}$ along each ray and the center of the arc area was used to identify the position of the tidal front and then quantify the movement of the front, and $T_{G f}$ was used to quantify the intensity of the tidal front. A snapshot of the SST consisting of 46 pairs of $D_{f}$ and $T_{G f}$ values can be obtained if the spatial coverage of the data is sufficient. However, no data are available at some rays due to cloud interference. Therefore, the spatially averaged values of $D_{f}$ and $T_{G f}$, denoted as $\left(\overline{D_{f}}\right)$ and $\left(\overline{T_{G f}}\right)$, respectively, were calculated from the available data and 
utilized to study the dependence of the variations of the front on spring-neap tidal cycles and month.

To examine the intra-tidal change in the front, it is necessary to know how to identify the SST data phase in a tidal cycle. In this study, the tidal current, synthesized from the harmonic constants of four major tidal constituents $\left(M_{2}, S_{2}, K_{1}\right.$, and $\left.O_{1}\right)$ at the center of Hayasui Strait (the black dot in Figure 1b) using T_TIDE program [24], was used to examine the relationship between the tidal current and the movement of the front. The harmonic constants are referred to in the publication, No. 742 Tidal Harmonic Constants Tables around Japanese Coast [25].

In order to evaluate the advection of the tidal current, we calculated the distance of a virtual particle that moves with the predicted tidal current velocity. Here, the distance of the virtual particle from the strait is called particle coordinator.

$$
L_{x}(t)=L_{x}(0)-\sum_{k=0}^{k=t-1}[u(k) \delta t],
$$

where $L_{x}$ is the particle coordinator (its maximum is tidal excursion) and its positive direction is southeastward; $L_{x}(0)$ is the distance from the center of the strait when the tidal current begins to flow southward; $u$ is the tidal current predicted at time $t$, and its positive direction is northwestward (Figure $1 \mathrm{~b}$ ); $k$ is the time index; $\delta t$ is the time interval ( $\delta t=10 \mathrm{~min}$ in this study). During southward ebb current phase, the particle coordinator increases.

\section{Results}

\subsection{Tidal Front Seasonal Variation}

Since the formation of tidal front needs buoyancy input that occurs only in warming season, the monthly mean SST (contours) and the magnitude of the SST gradients (colors) from April to September in the Bungo Channel (Figure 2) were used to study the seasonal variation of the front. The maximum temperature difference between the mixed and stratified areas was $2.5^{\circ} \mathrm{C}$ over a distance of $\sim 10 \mathrm{~km}$ in April, indicating the presence of a tidal front. The monthly averaged position of the tidal front changed little from April to August and disappeared in September. The intensity of the monthly averaged tidal front from April to July was approximately $0.25{ }^{\circ} \mathrm{C} / \mathrm{km}$ and significantly decreased in August. The seasonal variation of the tidal front is generally consistent with the report from ship-based observational data [5]. Yanagi and Tamaru [5] reported that the tidal front in Bungo Channel is formed in early spring and disappears in late September. From May to August, there is little variation in its average position but a wide range of variation in its intensity (Figure 8 in Yanagi and Tamaru, [5]). 


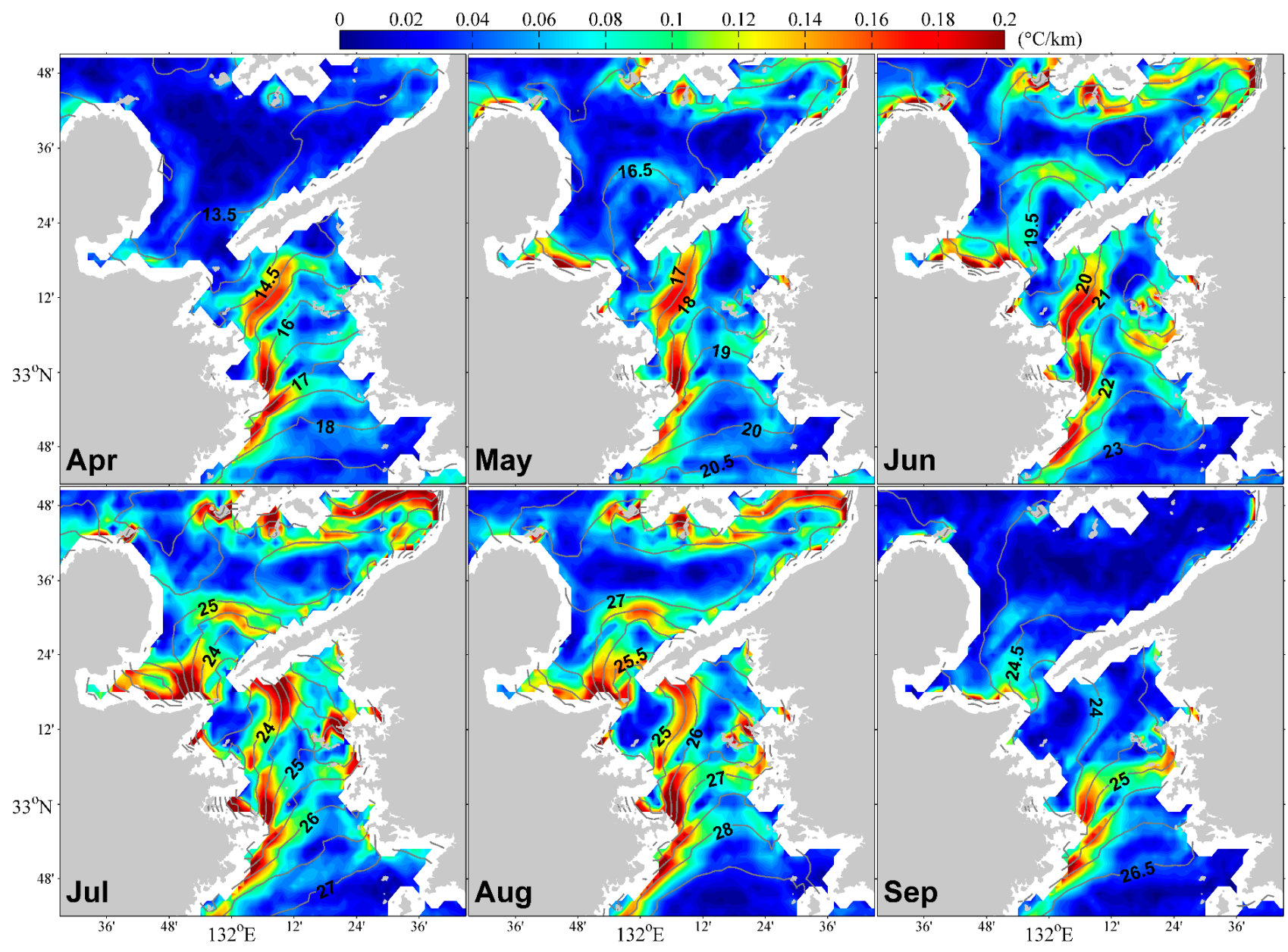

Figure 2. Monthly mean SST (contours) and the magnitude of the SST gradients (colors) from April to September in the Bungo Channel.

\subsection{Diurnal Variation of a Tidal Front during Spring Tide and Neap Tide}

To determine the intra-tidal variations in the position and intensity of the tidal front, the tidal front changes in a diurnal cycle must first be determined. Therefore, $24 \mathrm{~h}$ of continuous SST data during spring tide (Figure 3) and neap tide (Figure 4) were selected. Both datasets were selected in April but in different years because continuous data during both tides were not available in the same year.

During spring tide (Figure 3), the tidal front was closest to the strait at 10:00, and its intensity was minimal. Then, the tidal front moved southward with the intensity increased until 16:00, when it was farthest from the strait, and the intensity reached maximum. From 16:00, the tidal front moved northward as the intensity decreased until 22:00, when its position and intensity were the same as those at 10:00. The maximum movement of the tidal front during the northward flood current or southward ebb current was $15 \mathrm{~km}$ within $6 \mathrm{~h}$ (star symbol in Figure 3), and the intensity changed by $0.2^{\circ} \mathrm{C} / \mathrm{km}$ (pink plus symbol in Figure 5). In order to more quantitatively demonstrate the intra-tidal characteristics of the tidal front, we present Figure A1 in the Appendix A section to show the spatial-temporal variations in the position (distance from the center point of the strait to the thick gray line in Figure 3) and intensity (magnitude of the SST gradient on the thick gray line in Figure 3) of the front. 


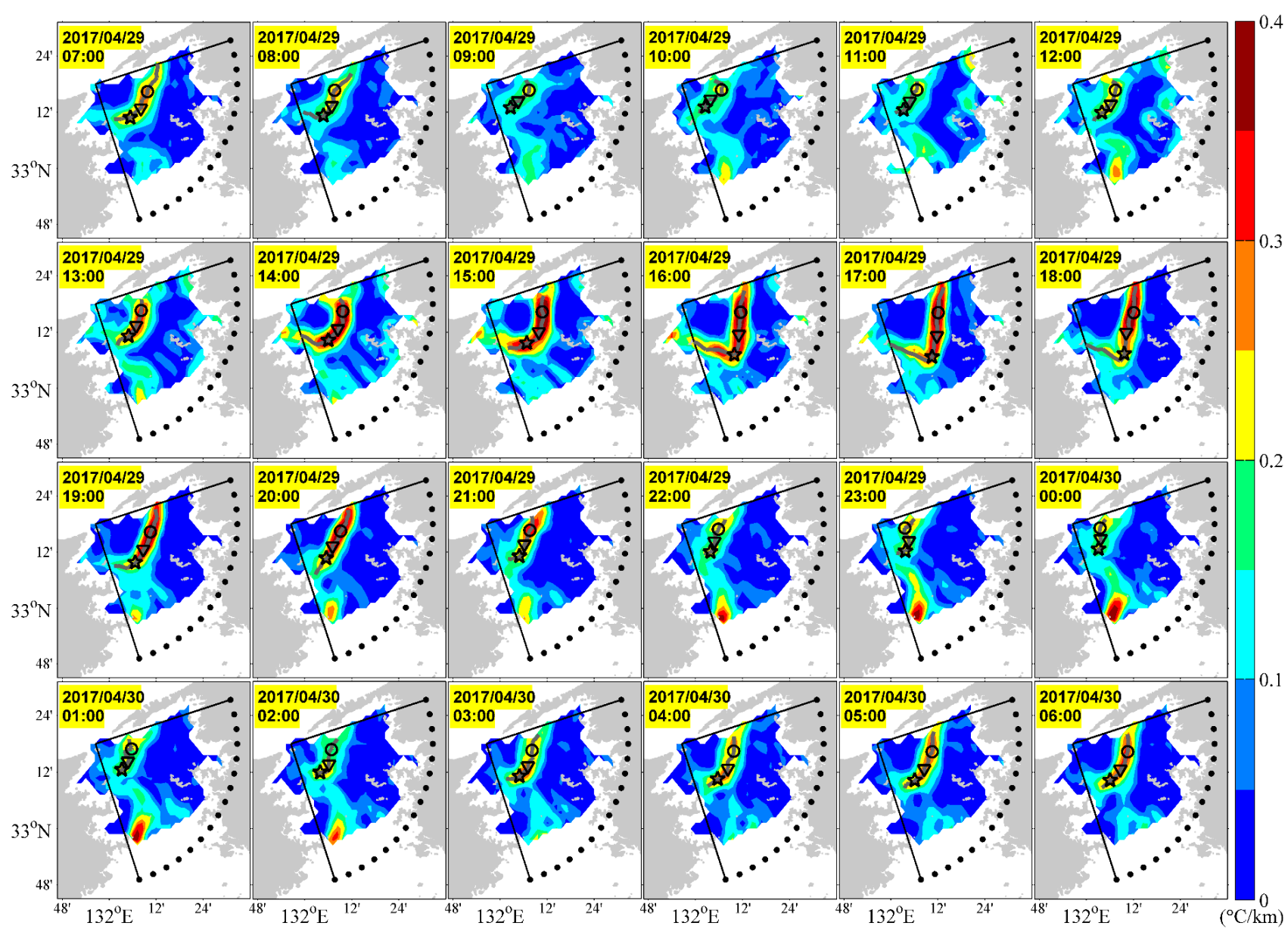

Figure 3. SST gradient magnitudes of the continuous hourly SST data from 07:00 29 April to 06:00 30 April 2017 (UTC+9) during spring tide. The thick black lines indicate the position of the tidal front, and the star, triangle, and circle denote three representative points. 


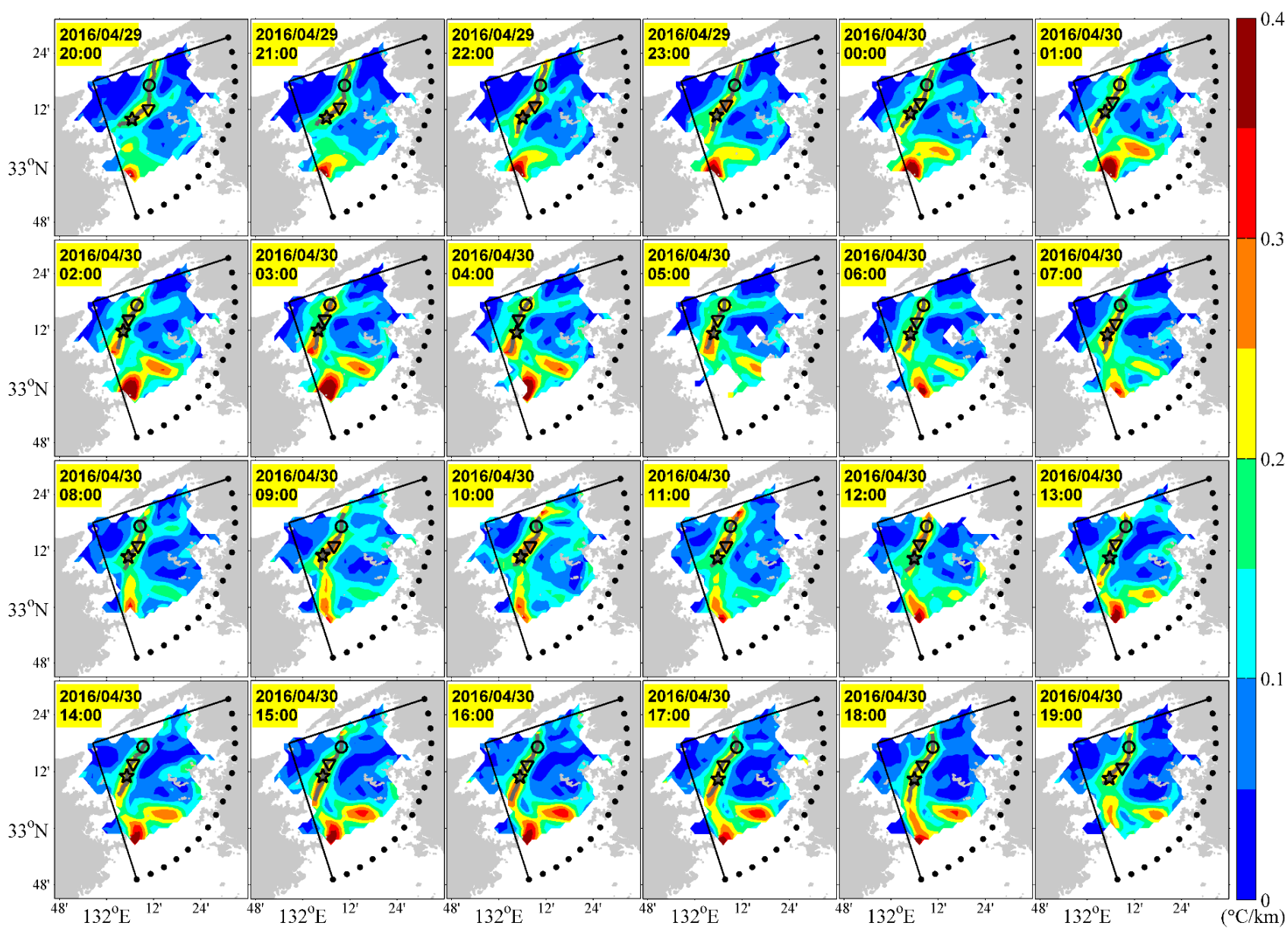

Figure 4. SST gradient magnitudes of the continuous hourly SST data from 20:00 29 April to 19:00 30 April 2016, during neap tide. The thick black lines indicate the position of the tidal front, and the star, triangle, and circle denote three representative points.

During neap tide (Figure 4), the intra-tidal variations of the tidal front were less than those during spring tide. The maximum movement of the tidal front (star symbol in Figure 4) was $8 \mathrm{~km}$ over $6 \mathrm{~h}$, and the intensity change was less than $0.1^{\circ} \mathrm{C} / \mathrm{km}$ (the blue plus symbol in Figure 5). The spatial-temporal variations in the position (distance from the center point of the strait to the thick gray line in Figure 4) and intensity (magnitude of the SST gradient on the thick gray line in Figure 4) of the front are given in Figure A2 in the Appendix A section. Based on these two datasets, the intra-tidal variations of the tidal front were likely controlled by semidiurnal tides, and the intra-tidal variations in position and intensity during spring tide were twice those during neap tide. Most of the data from April to August over the 5-year period confirm the dominant role of semidiurnal tides and the difference between spring tide and neap tide in tidal front intra-tidal variations (only April is shown in Figure 6). 


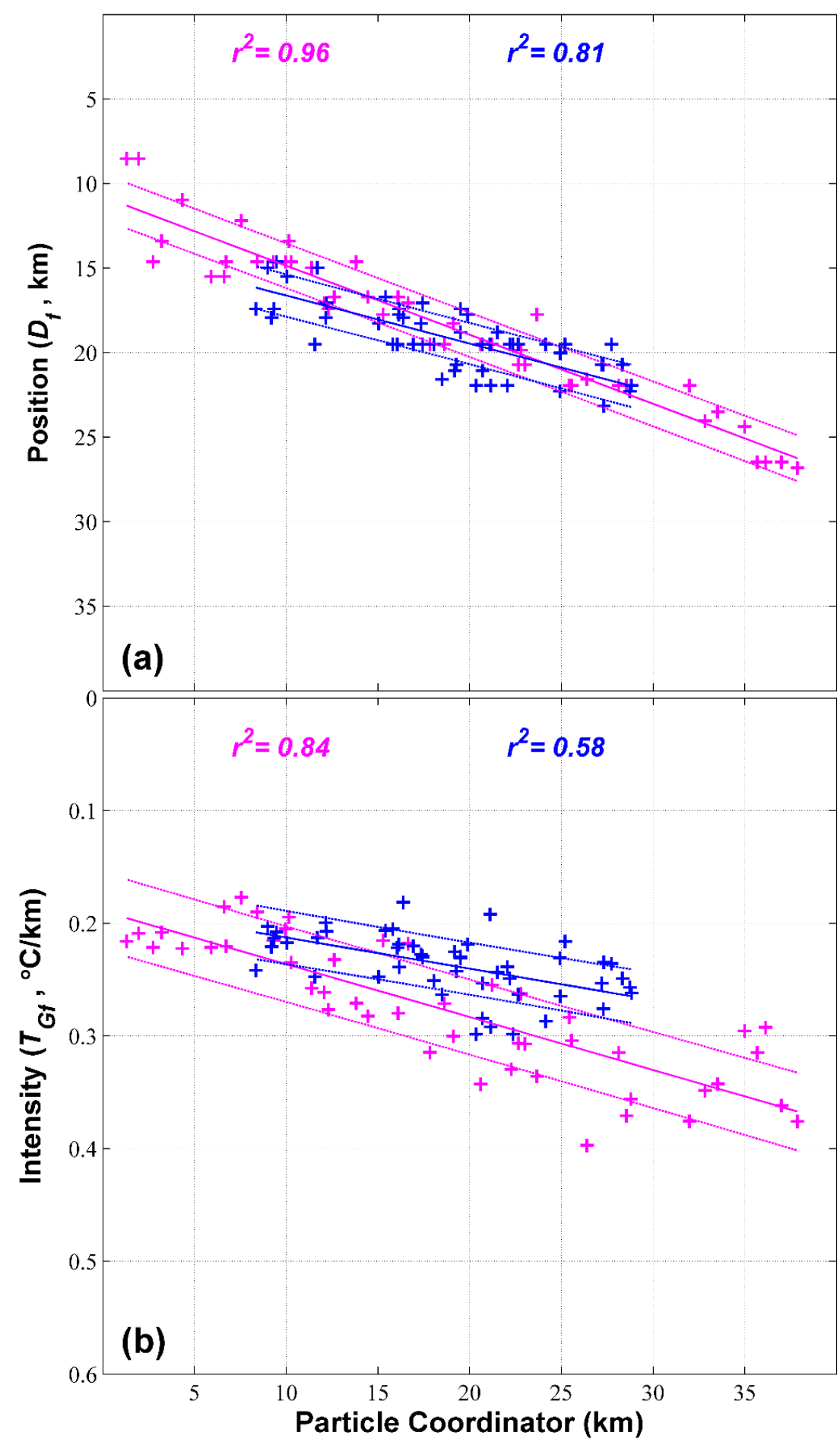

Figure 5. Lag correlations between the particle coordinator calculated by the predicted tidal current velocity using Equation (2) and (a) front position $\left(D_{f}\right.$, distance between the point denoted by a star in Figures 3 and 4 and the center of the strait), and (b) front intensity ( $T_{G f}$, magnitude of the SST gradient at the point denoted by a star in Figures 3 and 4). Pink and blue plus symbols represent the spring tide (Figure 3) and neap tide (Figure 4) values, respectively. Pink (blue) $r^{2}$ means the correlation coefficient at spring (neap) tide when the particle coordinator lags behind the tidal front position by one (one and half) hour. 


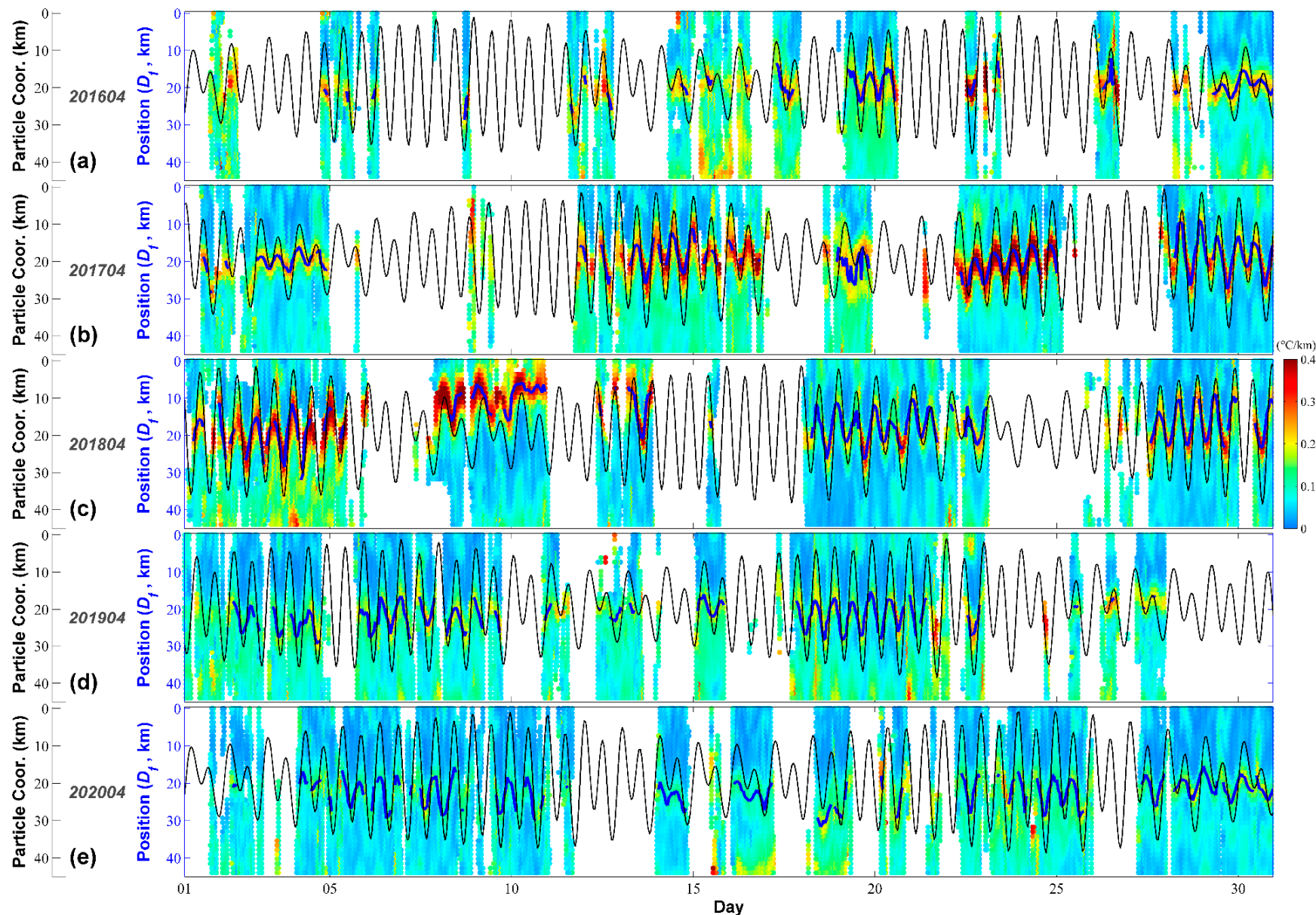

Figure 6. Time series of the front position $\left(D_{f}\right.$, distance between the point denoted by a star and the center of the strait (thick blue line) in Figures 3 and 4), the particle coordinator calculated by the predicted tidal current velocity using Equation (2) (black line), and the magnitude of the SST gradient along the line passing through the star in Figures 3 and 4 and the center of the strait (color) in April from 2016 (a) to 2020 (e).

\subsection{Tidal Front Intra-Tidal Movement and Tidal Current Advection}

The intra-tidal movement of the tidal front is highly dependent on the tidal current. As shown in Figure 7a, the tidal current inside the strait leads the tidal front position by approximately 2-3 h. During the flood current, the tidal currents and tidal front (red and black lines in Figure 7, respectively) move northward. As the tidal currents begin flowing southward (i.e., at the beginning of the ebb current), the front is closest to the strait. During the ebb current, the direction of the tidal current and the movement of the tidal front were southward. At the beginning of the flood current, the front is farthest from the strait. 

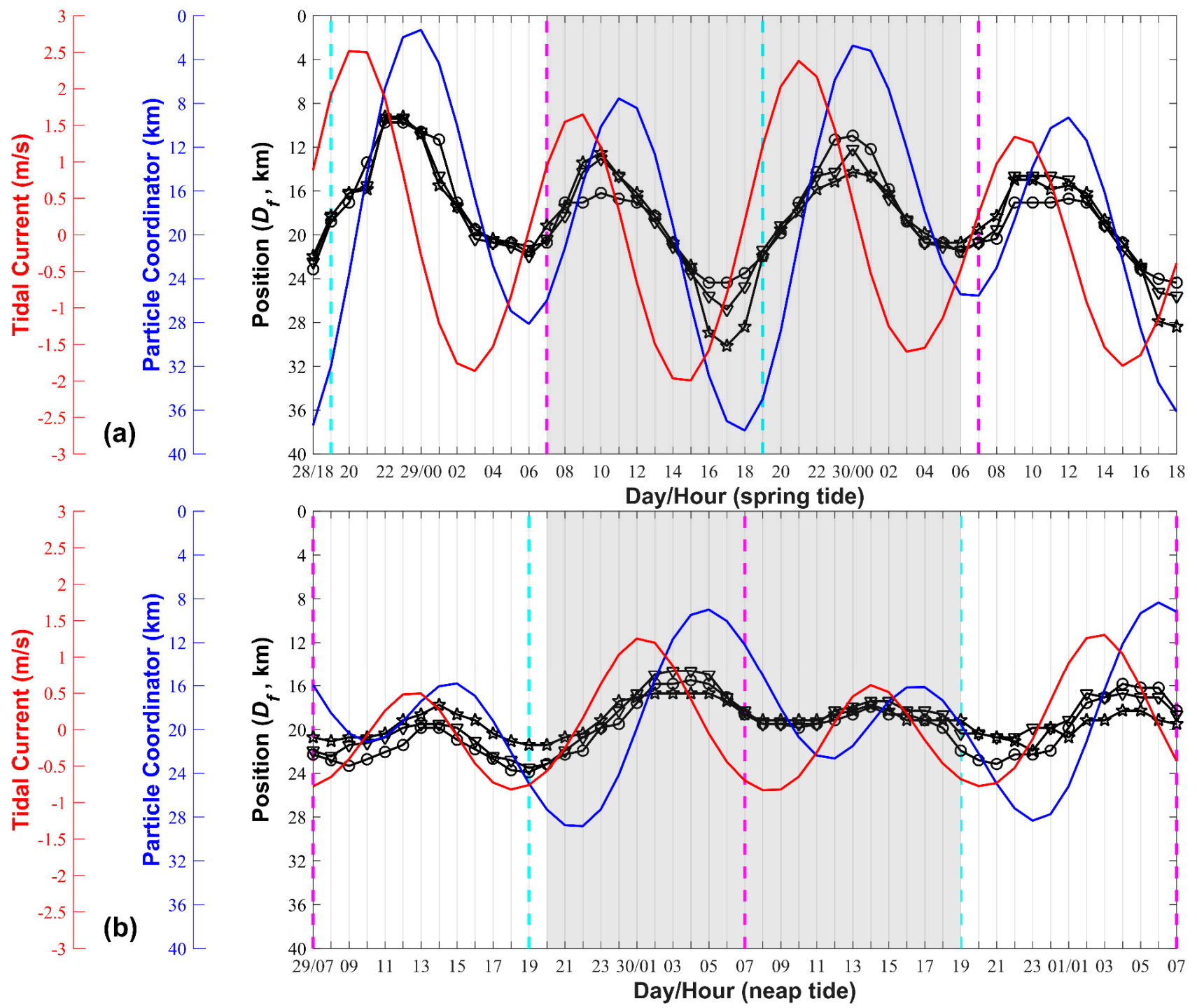

Figure 7. Predicted tidal current at the Hayasui Strait (red line), particle coordinator calculated by the tidal current velocity predicted by Equation (2) (blue line), and the front position ( $D_{f}$, distances from the center point of the strait to the tidal front of the star, triangle, and circle symbols in Figures 3 and 4) during the (a) spring tide and (b) neap tide periods of Figures 3 and 4, respectively. Positive tidal current values indicate northward flow. The black lines with the circle, triangle, and star symbols represent the distance of the front from the center of the strait, $D_{f}$, of the black circle, triangle, star symbols in Figures 3 and 4 . The time series length is $48 \mathrm{~h}$, and the shaded periods in (a) and (b) correspond to the data shown in Figures 3 and 4. The pink and cyan dotted lines indicate time of sunrise and sunset, respectively.

In general, the correspondence between the direction of the tidal current and the movement of the tidal front during neap tide is consistent with that during spring tide. During the neap tide period, the tidal current inside the strait leads the tidal front position by less than $2-3 \mathrm{~h}$ (Figure $7 \mathrm{~b}$ ).

To confirm the tidal front advection caused by the tidal currents, we calculated the particle coordinator using Equation (2). As shown in Figure 7, the tidal front position generally follows the position of the particles; however, the tidal excursion was approximately twice the movement range of the tidal front. This difference is caused by the spatial variation in the tidal currents that is strongest inside the strait but weakens with distance from the strait. The tidal current becomes significantly weaker during neap tide, producing a smaller tidal excursion; therefore, the intra-tidal movement of the tidal front during neap tide (Figure $7 \mathrm{~b}$ ) is less than that during spring tide (Figure 7a). 
The spatial variation in the tidal current also induced a different movement distance for each point along at 46 rays. The tidal front has a form of curve (Figure 3). The movement range changes spatially and is large at the center and becomes smaller as it approaches either side of the channel. Due to variation in the topography, the tidal current is strong in the central portion of the channel but weak along the coast (Figure 5a in Guo et al. [26]). The spatial change in the movement range of the front (Figure A1a) is consistent with spatial variations in the tidal currents. During neap tide, the tidal current in the central portion of the channel weakens, and the spatial variation in the tidal current decreases. A similar movement range of the front was observed at these representative points, which can be explained by the slight differences between the three black lines in Figure $7 \mathrm{~b}$.

During spring/neap tide, the lag-correlation coefficients between the tidal front movement (black line with star symbols in Figure 7) and the particle coordinator (blue line in Figure 7) are 0.92/0.89 for night-time (19:00-06:00) data and 0.98/0.70 for daytime (07:00-18:00) data. In general, there is a good correspondence between the intra-tidal movement of the tidal front and the tidal current advection both in night-time and daytime. However, the tidal front does not move at a specific time. For example, as shown in Figure $7 \mathrm{a}$, in the first $48 \mathrm{~h}$ of spring tide, the front is closest to the strait (approximately $10 \mathrm{~km}$ ), and between 22:00 and 23:00 on the 28th, the front remained relatively stationary. The lag-correlation coefficients between the tidal front movement and particle coordinator in Figure 7 are 0.96 and 0.81 during spring tide and neap tide, respectively (Figure 5a). Therefore, as the tidal currents weaken, such as during neap tide and near the end of flood and ebb tides during spring tide, other effects such as local winds and background residual currents may influence tidal front movement.

\subsection{Composite Analysis}

The above results about the intra-tidal variations in the position and intensity of the tidal front were from two continuous time series of SST data. However, the SST data are not always continuous due to the influence of cloud, and discontinuities are inevitable. Therefore, it is difficult to directly use this SST data to study the fortnightly variations of the tidal front and whether these variations change with months, which are possibly because the background residual current changes with months [27] and with spring tide and neap tide [28].

In this study, a composite SST dataset that consisted of data at the same tidal phase was utilized to overcome the data discontinuity issue. As discussed in Section 3.2, the tidal front generally moves in a semidiurnal tidal cycle. Therefore, the five tidal phases of the beginning of the southward ebb current, maximum ebb current, the end of the ebb current (i.e., the beginning of the northward flood current), maximum northward flood current, and the end of the flood current were selected according to the $M_{2}$ tide. These phases were utilized as indexes (numbers 1-5 in Figure 8) for the composite SST dataset preparation. First, it was necessary to confirm whether the tidal front intra-tidal variations in the SST composite dataset were consistent with the continuous time series SST dataset described in Section 3.2. Figure 8 shows the average SST (for the April months of 2016-2020) for the five phases during spring tide. During the ebb current phase (Indexes 1-3 in Figure 8), the tidal front moved southward, and its intensity increased. At the end of the ebb current phase (Index 3), the front was located farthest from the strait and exhibited maximum intensity. During the flood current phase (Indexes 3-5), the tidal front moved northward, and its intensity decreased. At the end of the flood current phase (Index 5), the front returned to its original position, and its intensity was the weakest. Compared to spring tide, the intra-tidal movement of the front during neap tide was smaller, and the intensity and intra-tidal change in the front were weaker (Figure 9). These results suggest that the intra-tidal variations of the tidal front of the composite dataset are consistent with those of the continuous dataset (Figures 3 and 4). Owing to the averaging performed to prepare the composite dataset, the composite dataset showed smaller intra-tidal variations in the position and intensity of the tidal front (Figures 3 and 4). 


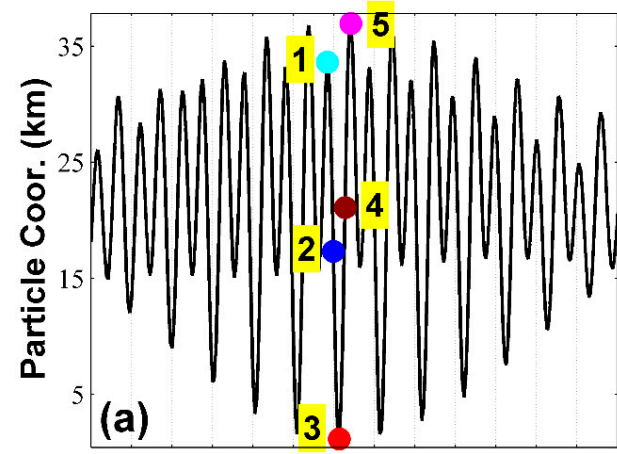

$\begin{array}{llllllllllllll}01 & 02 & 03 & 04 & 05 & 06 & 07 & 08 & 09 & 10 & 11 & 12 & 13\end{array}$

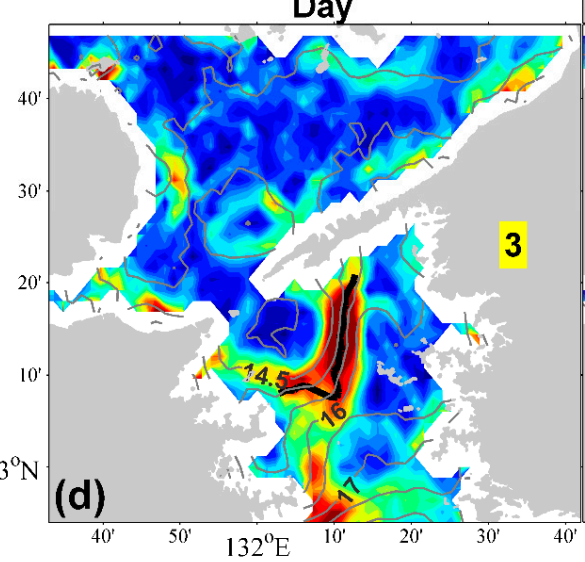

(b)

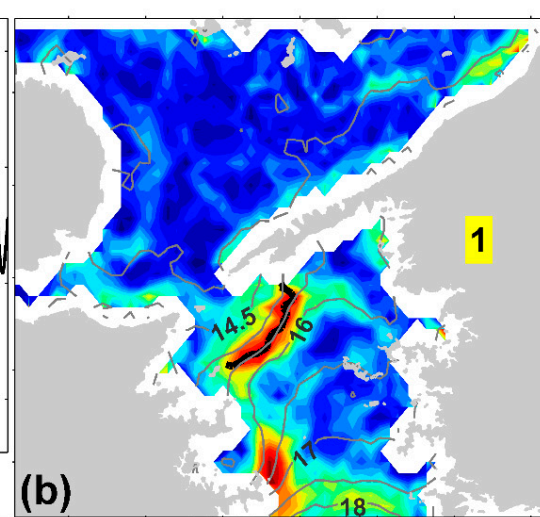

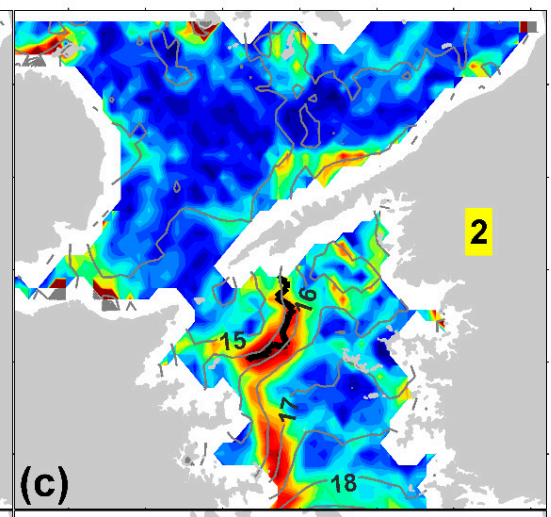
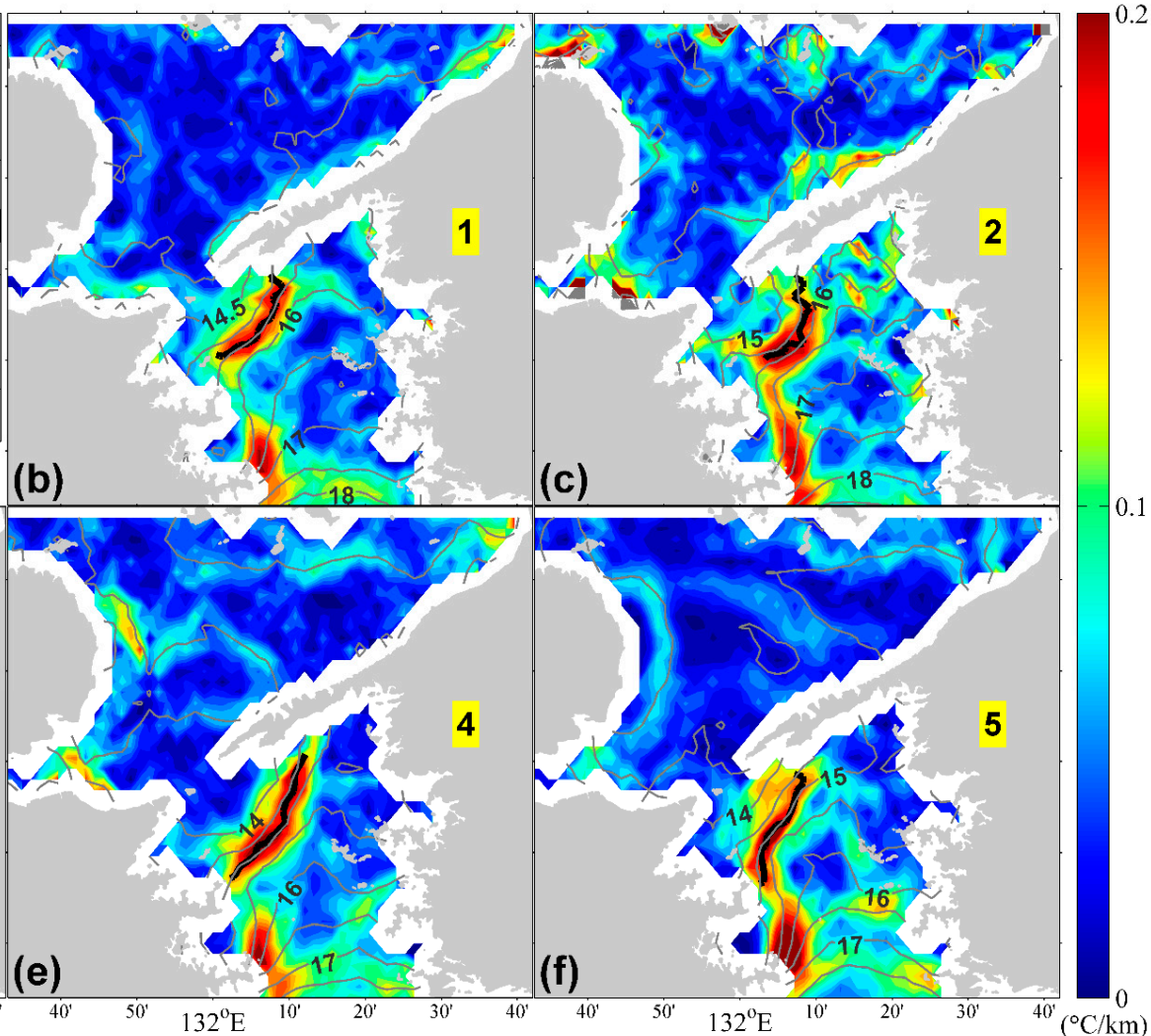

Figure 8. (a) Particle coordinator calculated by the tidal current velocity at Hayasui Strait using Equation (2) for 14 days. Five phases denoted as Indexes 1-5 were determined based on the $M_{2}$ tide as follows: the beginning of the southward ebb current, maximum ebb current, end of the ebb current (i.e., beginning of the northward flood current), maximum flood current, and end of the flood current. (b-f) Monthly (for the April months of 2016-2020) average SST (contours) and the magnitude of the SST gradients (colors) during spring tide corresponding to Indexes 1-5. The thick black lines denote the position of the tidal front.

The composite dataset method was utilized to examine the intra-tidal variations of the tidal front during spring tide and neap tide in different months. Therefore, the data processing procedure utilized to produce Figures 8 and 9 was performed to obtain the monthly averaged positions and intensities of the tidal front for the five tidal phases during spring tide and neap tide for each month from April to August utilizing data from 2016 to 2020 , and then the average positions $\left(\overline{D_{f}}\right)$ and intensities $\left(\overline{T_{G f}}\right)$ were obtained from 46 points along the tidal front (Figure 10). Generally, the positional intra-tidal variations identified in Figures 3-9 were the same in all months except August, when the intra-tidal movement of the tidal front was minimal. The increased intensity at the end of the ebb current phase during spring tide was observed in all months. 


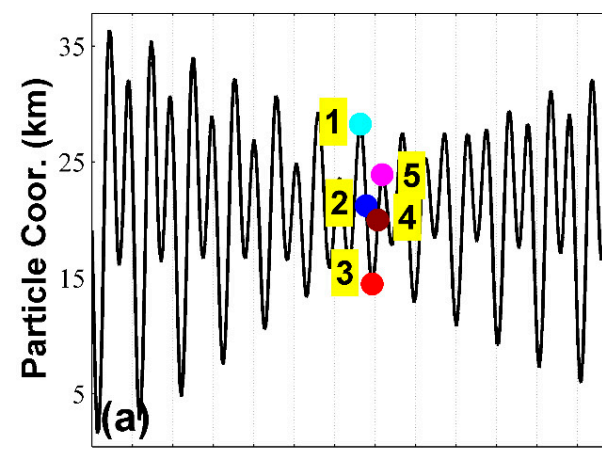

$\begin{array}{llllllllllllll}01 & 02 & 03 & 04 & 05 & 06 & 07 & 08 & 09 & 10 & 11 & 12 & 13\end{array}$

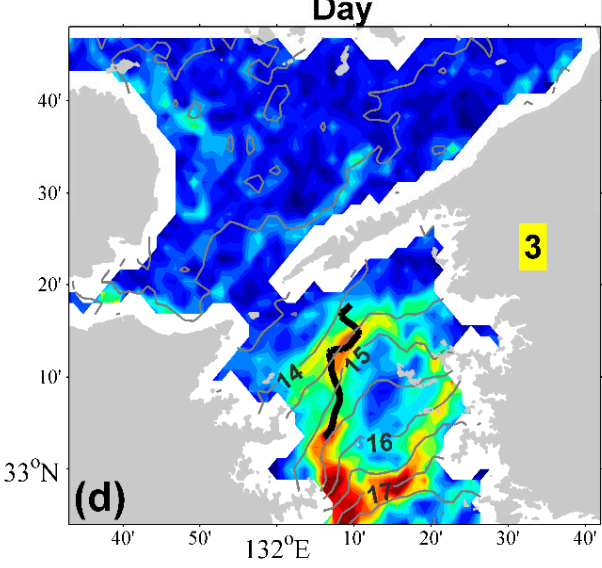

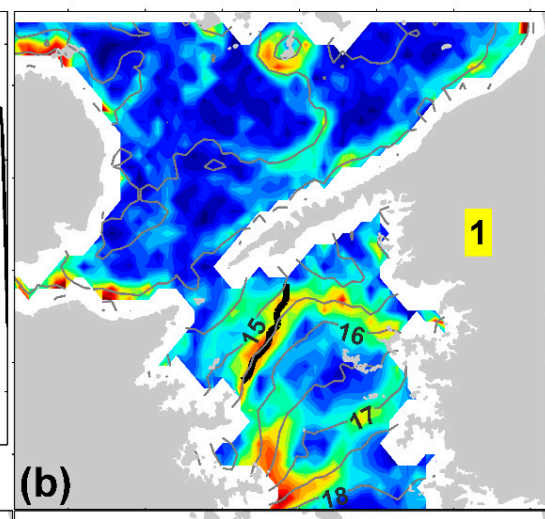
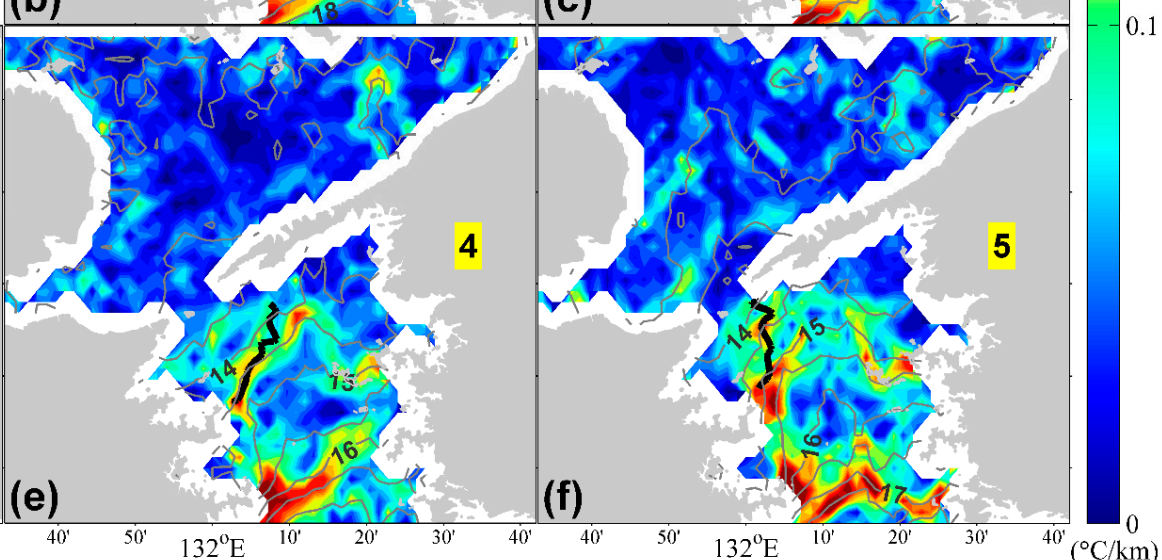

Figure 9. Same as Figure 8 but for the monthly averages during neap tide in April.

The intra-tidal movement of the tidal front from the temporally averaged composite dataset (Figures 8 and 9) were smaller than that from the continuous dataset (Figures 3 and 4). The intra-tidal movement of the tidal front was larger during spring tide than during neap tide (Figure 7). However, after performing spatial averaging on the temporally averaged dataset, there was no obvious difference for the intra-tidal movement between spring tide and neap tide, especially in April, July, and August (Figure 10). It might be related to the shape of the tidal front that was different at different phases (see the thick black lines in Figures 8 and 9). With the change in position of tidal front at 46 rays, the spatial averaging process likely reduces the difference of the intra-tidal movement between spring tide and neap tide. In other words, the intra-tidal movement of the tidal front has not only fortnight variation but also a strong spatial variation.

The mean position of the tidal front over a tidal period reverses in the studied months during spring tide and neap tide. In April and May, the tidal front was farther from the well-mixed strait during spring tide than during neap tide (pink and blue lines, respectively, in Figure 10), and this difference was minimal in June. In July, the position of the tidal front reverses, becoming closer to the well-mixed strait during spring tide than in neap tide. During spring tide, the tidal front gradually moves closer to the strait from a distance $>20 \mathrm{~km}$ in April and May to a distance $<20 \mathrm{~km}$ after June; however, during the neap tide, the tidal front moves further from the strait from a distance of $<20 \mathrm{~km}$ in April, May, and June to a distance $>20 \mathrm{~km}$ in July and August. Furthermore, the front has a larger intensity in April $\left(\sim 0.1^{\circ} \mathrm{C} / \mathrm{km}\right)$ during the spring tide than during the neap tide; however, this difference is minimal $\left(<0.1{ }^{\circ} \mathrm{C} / \mathrm{km}\right)$ in the other months. 


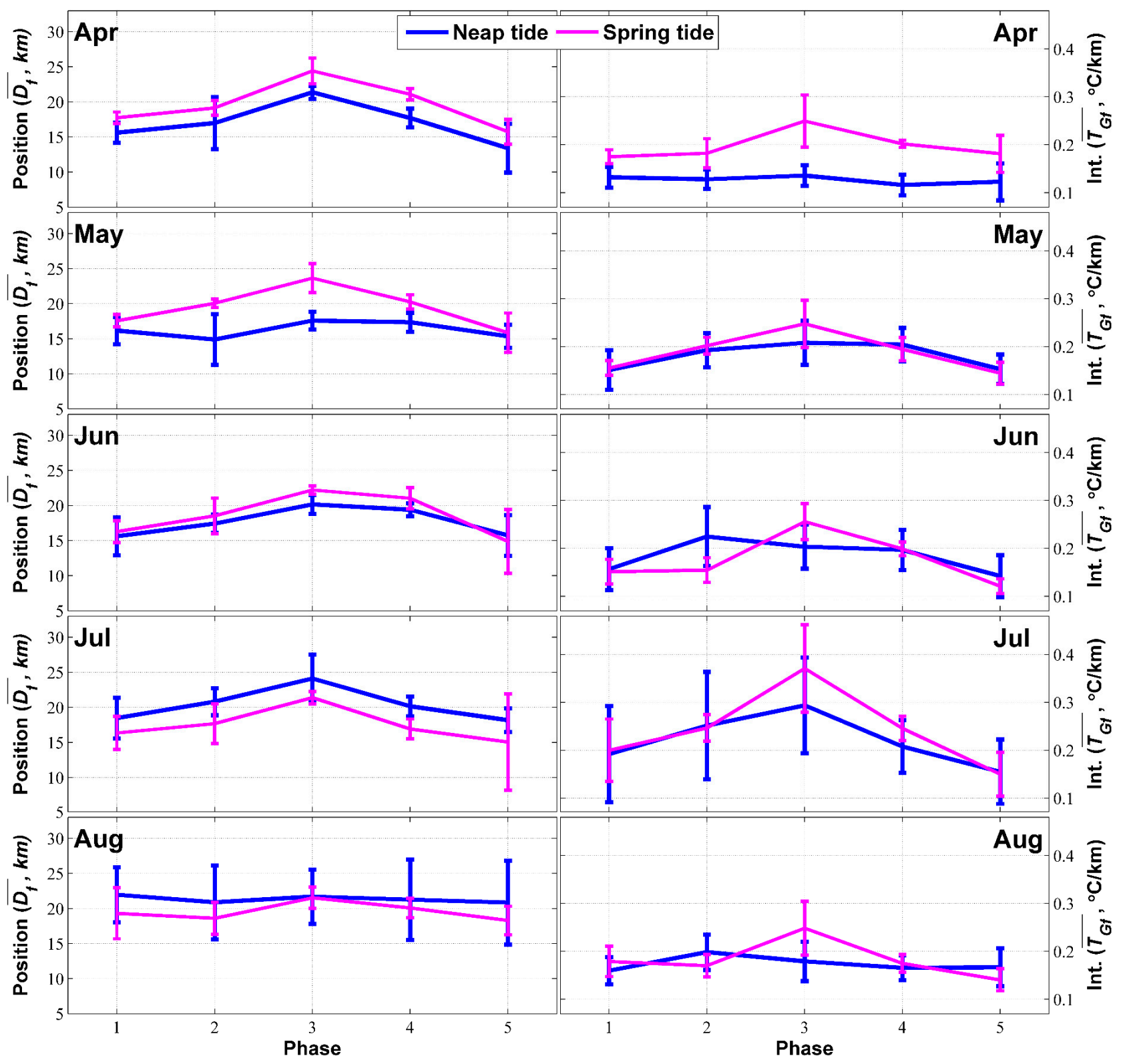

Figure 10. Five points on the pink and blue lines (spring tide and neap tide, respectively) represent the spatially averaged position $\left(\overline{D_{f}}\right.$, top left panel $)$ and intensity $\left(\overline{T_{G f}}\right.$, top right panel) of the temporally averaged tidal front shown as a thick black line in Figures $8 \mathrm{~b}-\mathrm{f}$ and $9 \mathrm{~b}-\mathrm{f}$, respectively. The bar is the standard deviation of the spatially averaged position and the spatially averaged intensity (left and right, respectively). The other panels correspond to the monthly results of May to August after the same data processing.

\section{Discussion and Conclusions}

In this study, five years of hourly SST data were utilized to examine the intra-tidal variations of the tidal front located near a strait in the Bungo Channel. An arc-like front separates the mixed water on the north side near the strait and the stratified water on the south side in the channel. A gradient-based method was employed to identify the position and intensity and quantify the intra-tidal variations of the front. The intra-tidal movement of the tidal front is mainly controlled by tidal current advection, and during a semidiurnal tidal cycle, the movement of the front corresponds with the ebb and flood currents. At the beginning of the ebb current, the front is located closest to the strait, and its intensity is relatively weak (" $\mathrm{H}$ " in Figure 11a). With ebb current development, the mixed water spreads to the stratified water area, causing the front to move southward. During 
this process, the water temperature contours become narrow, indicating an increased front intensity.
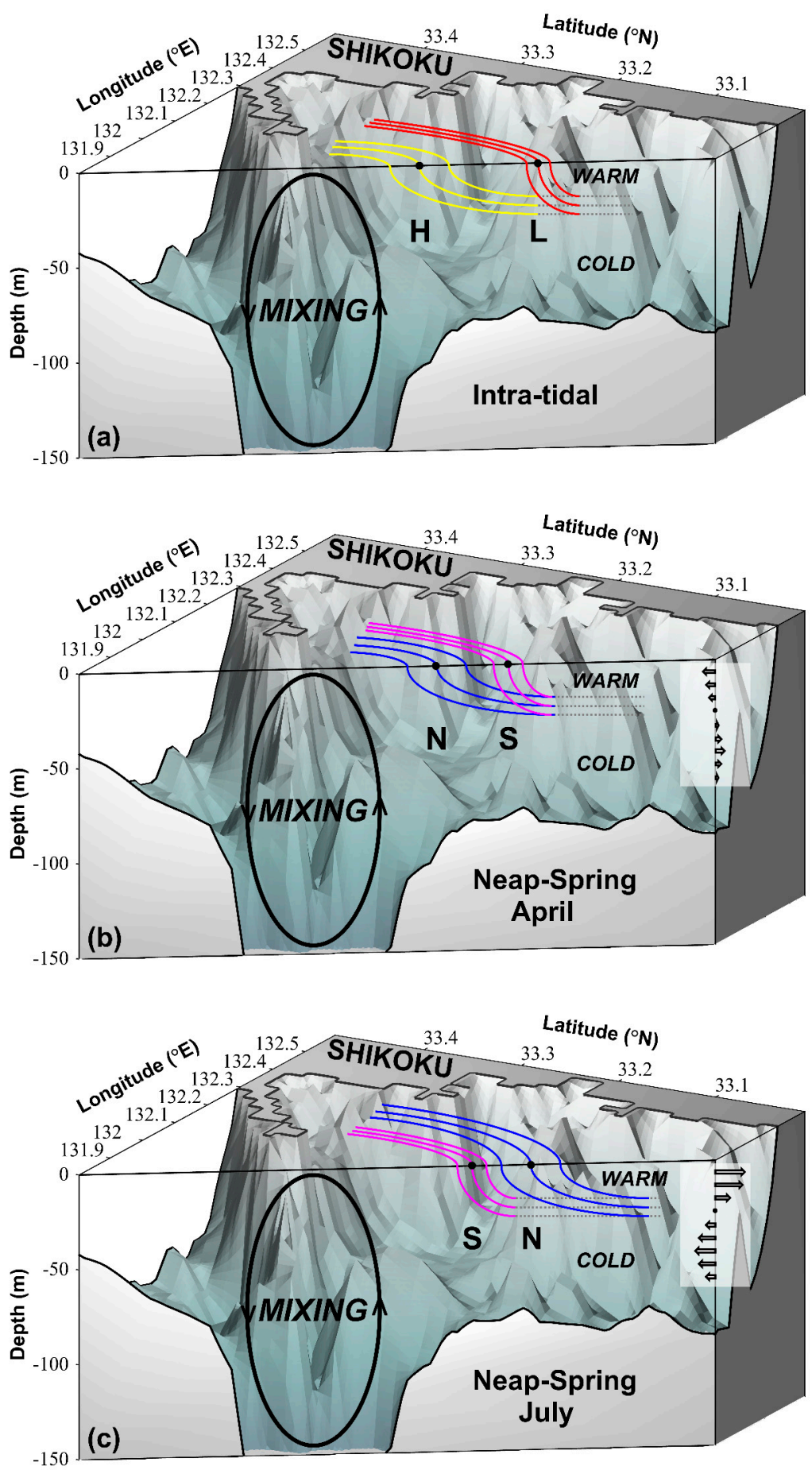

Figure 11. (a) Schematic of the intra-tidal variation in position and intensity of the tidal front. The yellow and red lines denote the isothermal lines for the front at the end of the flood $(\mathrm{H})$ and ebb $(\mathrm{L})$ current phases, which have small and large gradients, respectively. Schematics of the fortnightly variations of the front in (b) April and (c) July. Blue and pink lines indicate the isothermal lines during neap tide $(\mathrm{N})$ and spring tide $(\mathrm{S})$, and the horizontal arrows show the direction of the background residual currents. 
The intensity changes during ebb and flood currents are consistent with the results of a previous study on the effect of the horizontal motion of water with a horizontal buoyancy gradient on frontogenesis, which requires the convergence of the velocity component in the direction of the density gradient [29]. To explain this process, the temporal change in the temperature gradient across the front is expressed as follows:

$$
\frac{\partial^{2} T}{\partial t \partial x}=-\frac{\partial}{\partial x}\left(u \frac{\partial T}{\partial x}\right)=-\left(u \frac{\partial^{2} T}{\partial x^{2}}+\frac{\partial u}{\partial x} \frac{\partial T}{\partial x}\right),
$$

where $x$ is the distance from the strait to the channel, $u$ is the southward tidal current, $-u \frac{\partial^{2} T}{\partial x^{2}}$ is the advection of an existing gradient, and $-\frac{\partial u}{\partial x} \frac{\partial T}{\partial x}$ is the intensification or weakening of the local gradient due to the convergence or divergence of the current in the direction across the front [30]. Because this study defined the front with a maximum temperature gradient, $\frac{\partial^{2} T}{\partial x^{2}}$ is approximately zero. Additionally, the tidal current gradually weakens with increasing distance from the center of the strait; therefore, during the southward ebb current phase, $\frac{\partial u}{\partial x}<0$, indicating that convergence occurs. Due to the southward increase in water temperature, $\frac{\partial T}{\partial x}>0$, and consequently, $\frac{\partial}{\partial t}\left(\frac{\partial T}{\partial x}\right)>0$, indicating the intensity of the front increases during the ebb current phase. Consequently, the greatest intensity (" $\mathrm{L}$ " in Figure 11a) occurred at the end of the ebb current phase. During the northward flood current phase, the temperature gradient does not change its sign; however, $\frac{\partial u}{\partial x}$ becomes positive, indicating that divergence occurs; consequently, $\frac{\partial}{\partial t}\left(\frac{\partial T}{\partial x}\right)<0$, and the intensity of the front decreases.

This explanation of the intra-tidal intensity changes in the tidal front is also applicable to the spring-neap tidal cycle. For example, during spring tide and neap tide in April, the intensity of the front increases by 0.2 and $0.1{ }^{\circ} \mathrm{C} / \mathrm{km}$, respectively, at the end of the ebb current phase. The larger intra-tidal variation of the intensity of the front during spring tide compared to that during neap tide is likely attributed to the larger spatial variations of the tidal current (i.e., a larger convergence and divergence) during spring tide than in neap tide.

The monthly variation in the fortnightly variation of the tidal front depends on the background residual current. Utilizing a numerical model, Chang et al. [27] demonstrated that the residual current in the Seto Inland Sea has a two-layer structure in summer. In this study, although the residual current was weak in April, it exhibited northward and southward flow in the surface and bottom layers, respectively (Figure 11b). Due to the weak residual current, the change in the tidal front position during the spring-neap tidal cycle is mainly controlled by the stirring power produced by the tidal currents. Consequently, the mixed water area is larger, and the front is farther from the strait during spring tide than during neap tide ("S" and " $\mathrm{N}$ ", respectively, in Figure $11 \mathrm{~b}$ ).

From May through August, due to increased stratification and river water input, the residual current gradually changed to southward in the surface layer and northward in the bottom layer [27]. During this period, particularly after a heavy rain period around the end of June, the two-layer current (Figure 11c) and stratification intensified. The enhanced stratification in July limits tidal front spread during spring tide, consequently reducing the movement range of the front between spring tide and neap tide. The background residual current also has a fortnightly variation that is stronger during neap tide than during spring tide [28]; therefore, the tidal front moves farther south during neap tide than during spring tide ("N" and "S", respectively, in Figure 11c) in July.

This study presents a detailed description of the intra-tidal variations of a tidal front whose position is highly dependent on tidal and background residual currents and, therefore, has strong fortnightly and monthly variations. Additionally, the convergence and divergence of tidal currents are posited to cause tidal front intensification and weakening, respectively. Additional studies are anticipated on this subject because these phenomena probably occur globally in most tidal fronts. Because the satellite data utilized in this study 
were limited to SST data, future studies utilizing field survey data are needed to clarify the change in the vertical structure of the tidal front within a tidal cycle and a spring-neap tidal cycle.

Author Contributions: Visualization, writing_-original draft preparation, M.D.; conceptualization, writing-review and editing, funding acquisition, X.G. All authors have read and agreed to the published version of the manuscript.

Funding: This study was supported by a Grant-in-Aid for Scientific Research (MEXT KAKENHI grants: 17H01860, 20H01972).

Data Availability Statement: The Sea Surface Temperature (SST) data from April 2016 to August 2020 were obtained from the Japan Aerospace Exploration Agency website (https:/ / www.eorc.jaxa. jp/ptree/index.html, accessed on 24 April 2021).

Acknowledgments: The authors thank four reviewers for their helpful comments and Japan Aerospace Exploration Agency for providing the SST data. M. Dong thanks the China Scholarship Council (CSC) for supporting his stay in Japan.

Conflicts of Interest: The authors declare no conflict of interest.

\section{Appendix A. Appendix}

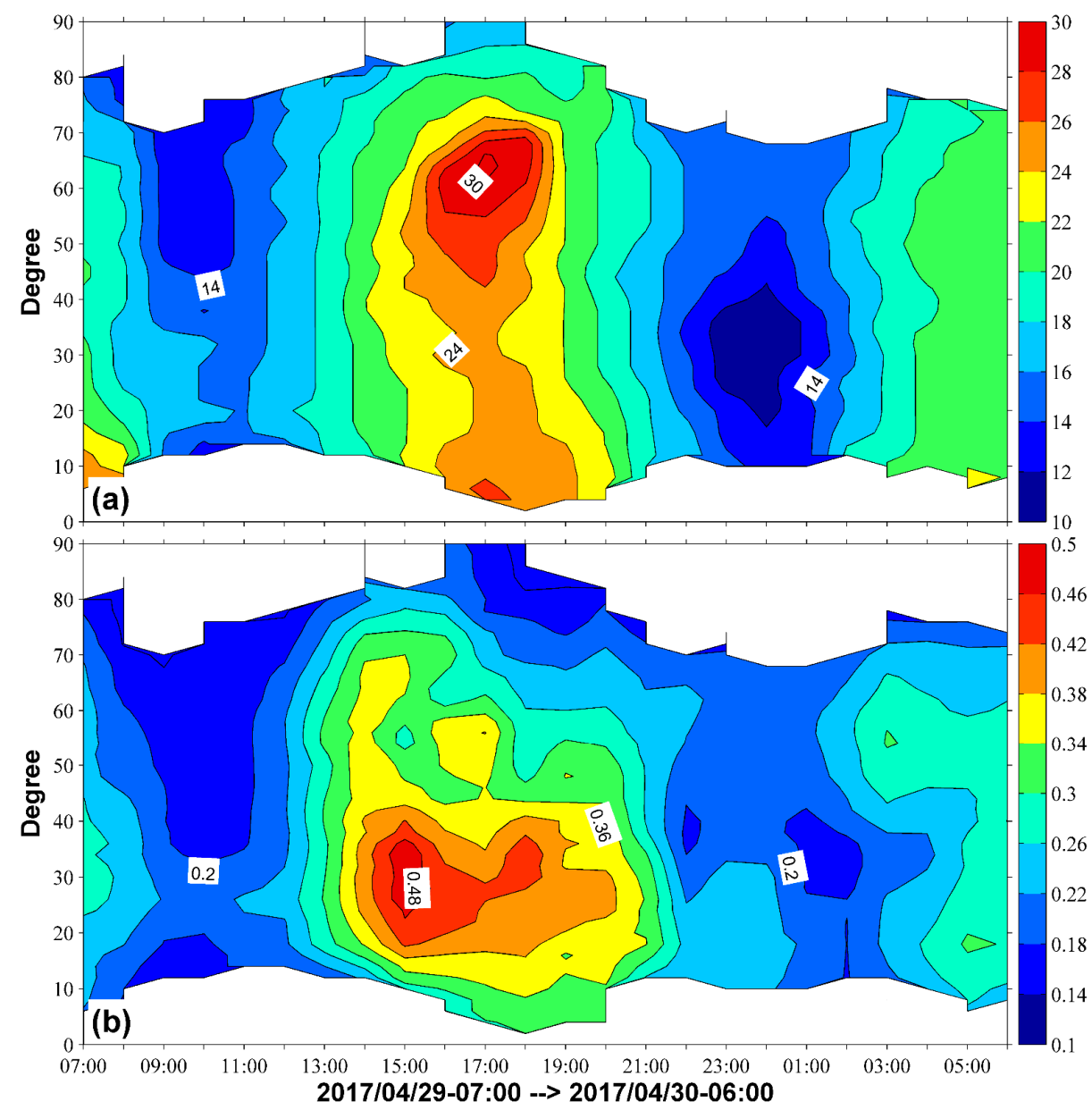

Figure A1. Spatial-temporal variations of (a) the front position $\left(D_{f}\right.$, distance from the center point of the strait to the thick gray line in Figure 3 ) and (b) the front intensity ( $T_{G f}$, magnitude of the SST gradient on the thick gray line in Figure 3). The ordinate is angle for 46 rays starting from the strait (Figure 1d). 


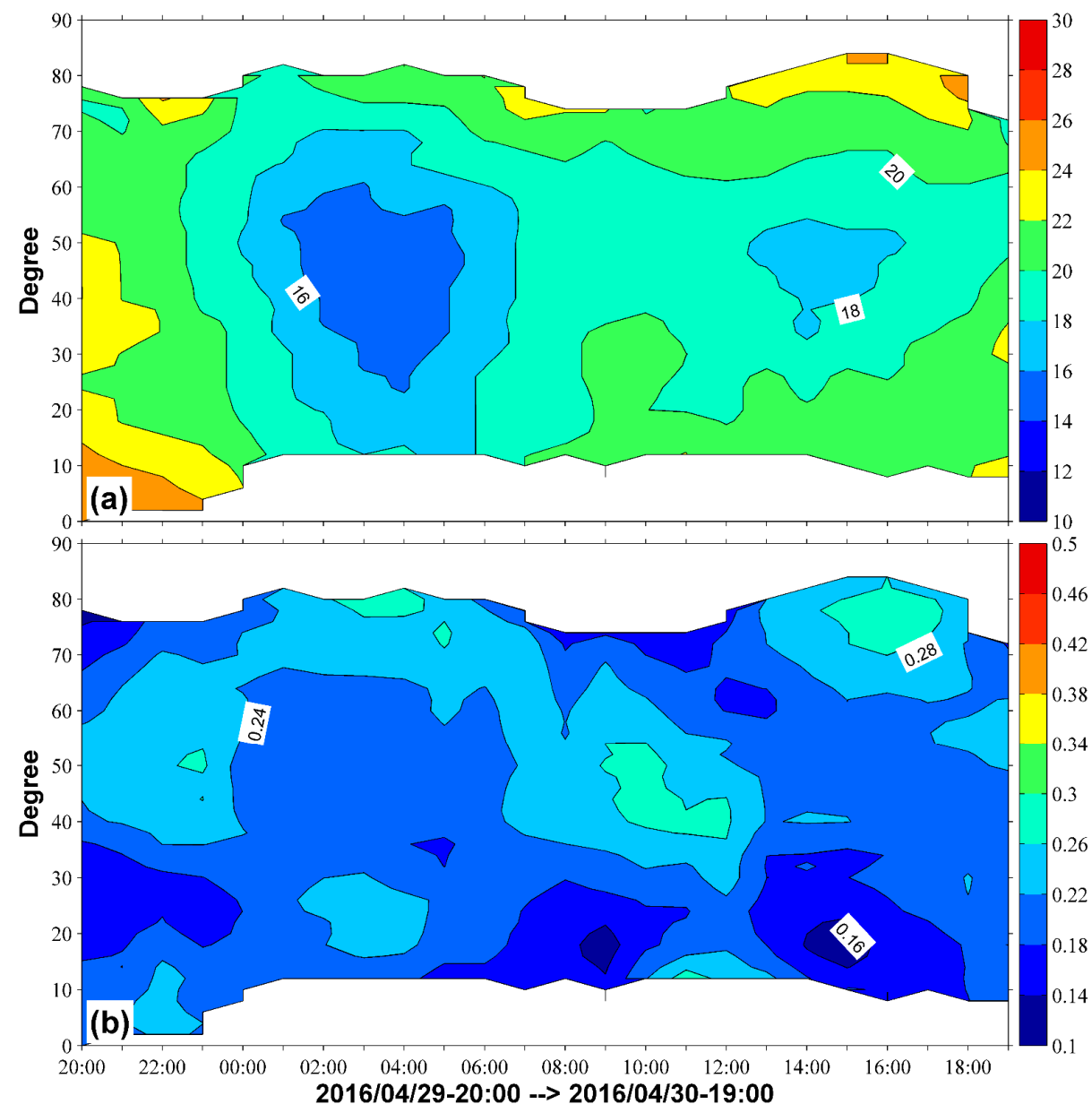

Figure A2. Spatial-temporal variations of (a) the front position $\left(D_{f}\right.$, distance from the center point of the strait to the thick gray line in Figure 4 ) and (b) the front intensity ( $T_{G f}$, magnitude of the SST gradient on the thick gray line in Figure 4). The ordinate is angle for 46 rays starting from the strait (Figure 1d).

\section{References}

1. Yanagi, T. Classification of "siome", streaks and fronts. J. Oceanogr. Soc. Jpn. 1987, 43, 149-158. [CrossRef]

2. Simpson, J.H.; Hunter, J.R. Fronts in the Irish Sea. Nature 1974, 250, 404-406. [CrossRef]

3. James, I.D. A model of the annual cycle of temperature in a frontal region of the Celtic Sea. Estuar. Coast. Mar. Sci. 1977, 5, 339-353. [CrossRef]

4. Simpson, J.H.; Pingree, R.D. Shallow Sea Fronts Produced by Tidal Stirring. In Oceanic Fronts in Coastal Processes; Bowman, M.J., Esaias, W.E., Eds.; Springer: Berlin/Heidelberg, Germany, 1977; pp. 29-42. ISBN 9783642669873.

5. Yanagi, T.; Tamaru, H. Temporal and spatial variations in a tidal front. Cont. Shelf Res. 1990, 10, 615-627. [CrossRef]

6. Takeoka, H.; Matsuda, O.; Yamamoto, T. Processes causing the chlorophyll a maximum in the tidal front in Iyo-nada, japan. J. Oceanogr. 1993, 49, 57-70. [CrossRef]

7. Sun, Y.-J.; Cho, Y.K. Tidal front and its relation to the biological process in coastal water. Ocean Sci. J. 2010, 45, 243-251. [CrossRef]

8. Brink, K.H. Instability of a tidal mixing front in the presence of realistic tides and mixing. J. Mar. Res. 2013, 71, 227-252. [CrossRef]

9. Simpson, J.H. The shelf-sea fronts: Implications of their existence and behaviour. Philos. Trans. R. Soc. Lond. Ser. A Math. Phys. Sci. 1981, 302, 531-546. [CrossRef]

10. Garrett, C.J.R.; Loder, J.W. Dynamical aspects of shallow sea fronts. Philos. Trans. R. Soc. Lond. Ser. A Math. Phys. Sci. 1981, 302, 563-581. [CrossRef]

11. Simpson, J.H.; James, I.D. Coastal and Estuarine Fronts. In Baroclinic Processes on Continental Shelves; Mooers, C.N.K., Ed.; American Geophysical Union: Washington, DC, USA, 1986; pp. 63-93. ISBN 9781118664995.

12. van Aken, H.M.; van Heijst, G.J.F.; Maas, L.R.M. Observations of Fronts in the North Sea. J. Mar. Res. 1987, 45, 579-600. [CrossRef]

13. Yanagi, T.; Koike, T. Seasonal variation in thermohaline and tidal fronts, Seto Inland Sea, Japan. Cont. Shelf Res. 1987, 7, 149-160. [CrossRef]

14. Wang, D.-P.; Chen, D.; Sherwin, T.J. Coupling between mixing and advection in a shallow sea front. Cont. Shelf Res. 1990, 10, 123-136. [CrossRef] 
15. Simpson, J.H.; Bowers, D. Models of stratification and frontal movement in shelf seas. Deep Sea Res. Part A Oceanogr. Res. Pap. 1981, 28, 727-738. [CrossRef]

16. Sun, Y.-J.; Isobe, A. Numerical study of tidal front with varying sharpness in spring and neap tidal cycle. J. Oceanogr. 2006, 62, 801-810. [CrossRef]

17. Sharples, J.; Simpson, J.H. Periodic frontogenesis in a region of freshwater influence. Estuaries 1993, 16, 74-82. [CrossRef]

18. Yanagi, T.; Takahashi, S. A tidal front influenced by river discharge. Dyn. Atmos. Ocean. 1988, 12, 191-206. [CrossRef]

19. Yanagi, T.; Matsuda, O.; Tanabe, S.; Uye, S. Interdisciplinary study on the tidal front in the Bungo Channel, Japan. Phys. Estuaries Costal Seas 1992, 40, 617-630. [CrossRef]

20. Pisoni, J.P.; Rivas, A.L.; Piola, A.R. On the variability of tidal fronts on a macrotidal continental shelf, Northern Patagonia, Argentina. Deep Sea Res. Part II Top. Stud. Oceanogr. 2015, 119, 61-68. [CrossRef]

21. Japan Aerospace Exploration Agency Himawari Monitor. Available online: https://www.eorc.jaxa.jp/ptree/index.html (accessed on 27 October 2015).

22. Kurihara, Y.; Murakami, H.; Kachi, M. Sea surface temperature from the new Japanese geostationary meteorological Himawari-8 satellite. Geophys. Res. Lett. 2016, 43, 1234-1240. [CrossRef]

23. Donlon, C.J.; Martin, M.; Stark, J.; Roberts-Jones, J.; Fiedler, E.; Wimmer, W. The Operational Sea Surface Temperature and Sea Ice Analysis (OSTIA) system. Remote Sens. Environ. 2012, 116, 140-158. [CrossRef]

24. Pawlowicz, R.; Beardsley, B.; Lentz, S. Classical tidal harmonic analysis including error estimates in MATLAB using T TIDE. Comput. Geosci. 2002, 28, 929-937. [CrossRef]

25. Maritime Safety Agency, Hydrographic and Oceanographic Department. Tidal Harmonic Constants Tables Around Japanese Coast, 2nd ed.; Maritime Safety Agency: Tokyo, Japan, 1992; (in Japanese). Available online: https://www1.kaiho.mlit.go.jp/ (accessed on 24 April 2021).

26. Guo, X.; Harai, K.; Kandeda, A.; Takeoka, H. Simulation of Tidal Currents and Nonlinear tidal interactions in the seto inland sea, japan. Rep. Res. Inst. Appl. Mech. Kyushu Univ. 2013, 145, 43-52.

27. Chang, P.-H.; Guo, X.; Takeoka, H. A numerical study of the seasonal circulation in the Seto Inland Sea, Japan. J. Oceanogr. 2009, 65, 721-736. [CrossRef]

28. Yu, X.; Guo, X.; Takeoka, H. Fortnightly variation in the bottom thermal front and associated circulation in a semienclosed sea. J. Phys. Oceanogr. 2016, 46, 159-177. [CrossRef]

29. Simpson, J.E.; Linden, P.F. Frontogenesis in a fluid with horizontal density gradients. J. Fluid Mech. 1989, 202, 1-16. [CrossRef]

30. O'Donnell, J. Surface fronts in estuaries: A review. Estuaries 1993, 16, 12-39. [CrossRef] 